\title{
Sykepleiere rangerer sykdommer etter prestisje
}

\section{Hjerteinfarkt på topp, fibromyalgi på bunn. Sykepleiere mener at noen sykdommer har høyere prestisje enn andre. Det kan påvirke måten de behandler pasienter på.}

\section{Lars E.F. Johannessen}

Sosiolog og postdoktor

Institutt for sosialfag, Oslomet - storbyuniversitetet

\section{Prestisje Prioritering Kultur}

\section{Hovedbudskap}

En spørreunders $\varnothing$ kelse viser at sykepleiere rangerer sykdommer etter prestisje.

Rangeringene antyder en «cure»- fremfor en «care»-tilnærming til helsearbeid og kan ha konsekvenser for hvordan pasienter behandles og prioriteres. Sykepleiere bør derfor reflektere over hvorvidt sykdommers prestisje kan ha betydning for deres egen praksis.

En rekke studier viser at leger rangerer sykdommer i et prestisjehierarki, der sykdommer vurderes som mer eller mindre «fine», spennende, ærefulle eller interessante (1-6). På toppen av prestisjehierarkiet finnes sykdommer som hjerteinfarkt, hjerneslag og leukemi. I bunnen finner man skrumplever, angstnevroser og fibromyalgi (3). 
I en nylig publisert artikkel spurte vi om også sykepleiere rangerer sykdommer etter prestisje (7). Svaret er ja: Vi finner at sykepleiere rangerer sykdommer i et prestisjehierarki, som minner overraskende mye om legenes rangeringer.

\section{$\equiv$ «Sykepleiere rangerer sykdommer i et prestisjehierarki.»}

Artikkelens funn antyder at sykepleiere vurderer sykdommer ut fra et «cure»-perspektiv (med vekt på snevre medisinske idealer) framfor et «care»-perspektiv (med vekt på helhetlig omsorg og pleie) (8).

Da slike rangeringer kan ha konsekvenser for hvordan man møter og prioriterer pasienter, er det viktig at sykepleiere reflekterer over hvorvidt sykdommers prestisje kan ha betydning for egen praksis.

\section{Prestisje er et sosialt fenomen}

I forskning har prestisjebegrepet røtter tilbake til sosiologen Max Weber (9). Weber så prestisje som et av tre grunnleggende lagdelingsprinsipper, sammen med penger og makt.

Prestisje viser til variasjoner i noe eller noens status eller anseelse og er et grunnleggende sosialt fenomen:

Prestisjevurderinger viser nemlig ikke til hva enkeltpersoner foretrekker, men til folks oppfatninger av hva som er mer og mindre verdsatt i det samfunnet de tilhører (9).

Det er for eksempel vanlig at enkeltindivider foretrekker å se lavbudsjetts actionfilmer, samtidig som de anerkjenner at såkalt kunstfilm nyter høyere prestisje (6).

\section{Legene snakket om «finere» sykdommer}

Koplingen mellom prestisje og sykdom springer ut av Dag Albums erfaringer med legers pauseromsprat (10).

Da Album var stipendiat ved en institusjon som videreutdanner leger, overhørte og deltok han i mange samtaler om legers arbeid. Han merket seg at legene iblant ga uttrykk for at noen sykdommer var «finere» enn andre og fikk dem da til å rangere ulike sykdommer. Legene var overraskende enige om hva som var høyt og lavt. 


\section{Helsepersonell rangerte sykdommer}

Inspirert av forskningen på yrkers prestisje (11), bestemte Album seg for å sende ut et spørreskjema der leger og annet helsepersonell ble bedt om å rangere 38 sykdommer på en prestisjeskala fra 1 til 9 .

For å unngå personlige meninger eller «moraliserende» svar, ble respondentene bedt om å rangere sykdommene etter hvordan de mente «helsepersonell flest» vurderer dem (1).

\section{$\equiv$ «Hjerteinfarkt, blodkreft og hjernesvulst var de høyest rangerte sykdommene.»}

Respondentene viste seg å være i stand til å rangere sykdommer langs hele prestisjeskalaen (1-9), og ikke bare i topp- og bunnpunkter. Rangeringene hadde også en høy grad av konsistens: Hjerteinfarkt, blodkreft og hjernesvulst var de høyest rangerte sykdommene, mens angstnevrose, skrumplever og fibromyalgi ble rangert lavest (1).

Unders $\varnothing$ kelsen ble gjentatt to ganger senere, senest i 2014 (3). Resultatene har vist seg å være de samme, noe som tyder på at prestisjevurderingene er et stabilt trekk ved legenes kultur.

\section{Logikken i legenes rangeringer}

Systematikken i legenes prestisjevurderinger antyder at de er strukturert etter bestemte kriterier. Basert på feltarbeidserfaringer og intervjuer med leger har Album og Westin identifisert følgende tre klynger av prestisjekriterier (2).

1. Sykdommen og dens typiske forløp: Sykdommer høyt oppe i kroppen (helst hjernen eller hjertet), som er akutte og dødelige, med klart påviselige tegn og kjente årsaker, har typisk høy prestisje.

2. Sykdommens typiske behandling: Sykdommer som lar leger bruke høyteknologisk utstyr, og som innebærer en dramatisk og effektiv intervensjon i sykdomsforløpet, tilkjennes ofte høy prestisje.

3. Sykdommens typiske pasient: Sykdommer som rammer unge, kanskje helst menn, der pasientens sykdomsforståelse ikke er i konflikt med legens, og som verken gjør pasienten vansiret eller hjelpeløs, har typisk høy prestisje. 


\section{Vi undersøkte sykepleiernes vurderinger}

Som det ovenstående viser, har forskningen på sykdommers prestisje nærmest utelukkende studert legers prestisjevurderinger.

For å utvide perspektivet, bestemte Dag Album, Erik Børve Rasmussen og undertegnede seg for å unders $\varnothing$ ke hvorvidt også sykepleiere vurderer sykdommer etter prestisje.

Vi benyttet datasettet fra den siste runden med spørreunders $\varnothing$ kelser i 2014, og analyserte svarene til de 122 sykepleierne i utvalget. Sykepleierne hadde fått den samme oppgaven som legene: å vurdere 38 sykdommer på en skala fra 1 til 9 etter hvor prestisjefylte de er blant «helsepersonell flest» (7).

\section{Sykepleierne rangerer sykdommer etter prestisje}

Resultatene er publisert i en artikkel i Journal of Advanced Nursing (7) og gjengitt i tabell 1. De viser at sykepleierne rangerer sykdommer etter prestisje, med hjerteinfarkt, leukemi og hjernesvulst på topp og depressiv nevrose, angstnevrose og fibromyalgi på bunnen.

\section{三 «Vi finner også en slående likhet mellom sykepleiernes og legenes rangeringer.»}

Vi finner også en slående likhet mellom sykepleiernes og legenes rangeringer (3). Avstanden i gjennomsnittsskår er mindre enn 0,5 poeng for alle unntatt de fire sykdommene apopleksi, grå stær, meniskruptur og hjerteinfarkt (tabell 1). 
Tabell 1. Sykdommers prestisje: rang, gjennomsnittskår (score) på en skala fra 1 til 9 og standardavvik (SD), sortert etter sykepleiernes rangeringer.

\begin{tabular}{|c|c|c|c|c|c|c|}
\hline \multirow[b]{3}{*}{ Sykdom } & \multicolumn{3}{|c|}{ Sykepleiere } & \multicolumn{3}{|c|}{ Leger } \\
\hline & \multicolumn{3}{|c|}{ Antall = 122} & \multicolumn{3}{|c|}{ Antall = 291} \\
\hline & $\#$ & Score & SD & $\#$ & Score & SD \\
\hline Hjerteinfarkt & 1 & 7,4 & 1,3 & 2 & 6,7 & 1,6 \\
\hline Leukemi & 2 & 7,3 & 1,3 & 1 & 6,9 & 1,5 \\
\hline Hjernesvulst & 3 & 7,2 & 1,5 & 2 & 6,7 & 1,7 \\
\hline Testikkelkreft & 4 & 6,8 & 1,6 & 4 & 6,6 & 1,6 \\
\hline Tykktarmskreft & 5 & 6,5 & 1,5 & 7 & 6,1 & 1,5 \\
\hline Miltruptur & 6 & 6,4 & 1,6 & 5 & 6,4 & 1,5 \\
\hline Lungeemboli & 7 & 6,3 & 1,6 & 5 & 6,4 & 1,5 \\
\hline Bukspyttkjertelkreft & 8 & 6,1 & 1,6 & 12 & 5,7 & 1,7 \\
\hline Meniskruptur & 9 & 6,0 & 1,9 & 14 & 5,4 & 1,7 \\
\hline Kreft i eggstokk & 9 & 6,0 & 1,5 & 9 & 5,9 & 1,5 \\
\hline Angina pectoris & 11 & 5,9 & 1,6 & 11 & 5,8 & 1,5 \\
\hline Nyrestein & 11 & 5,9 & 1,6 & 14 & 5,4 & 1,4 \\
\hline Skjoldbrukskjertelkreft & 11 & 5,9 & 1,6 & 9 & 5,9 & 1,6 \\
\hline Grå stær & 14 & 5,8 & 1,8 & 19 & 5,2 & 1,7 \\
\hline Ekstrauterin graviditet & 15 & 5,7 & 1,8 & 8 & 6,0 & 1,7 \\
\hline Nyresvikt & 15 & 5,7 & 1,6 & 16 & 5,3 & 1,6 \\
\hline Lungekreft & 17 & 5,6 & 2,0 & 16 & 5,3 & 1,9 \\
\hline Blindtarmbetennelse & 18 & 5,1 & 1,8 & 13 & 5,6 & 1,7 \\
\hline Ankelbrudd & 18 & 5,1 & 1,7 & 20 & 5,1 & 1,6 \\
\hline Ulcerøs kolitt & 20 & 4,8 & 1,4 & 16 & 5,3 & 1,4 \\
\hline Ulcerøs duodeni & 21 & 4,7 & 1,4 & 21 & 5,0 & 1,3 \\
\hline Ischias & 22 & 4,6 & 1,4 & 23 & 4,9 & 1,3 \\
\hline Astma & 23 & 4,5 & 1,3 & 21 & 5,0 & 1,3 \\
\hline Bekhterevs sykdom & 23 & 4,5 & 1,4 & 26 & 4,8 & 1,4 \\
\hline Lårhalsbrudd & 23 & 4,5 & 1,6 & 27 & 4,7 & 1,5 \\
\hline Multippel sklerose & 26 & 4,4 & 1,3 & 23 & 4,9 & 1,6 \\
\hline Leddgikt & 27 & 4,1 & 1,3 & 28 & 4,6 & 1,3 \\
\hline Lyskebrokk & 27 & 4,1 & 1,7 & 29 & 4,2 & 1,5 \\
\hline Cerebral parese & 29 & 3,8 & 1,4 & 30 & 3,9 & 1,5 \\
\hline Apopleksi & 30 & 3,5 & 1,5 & 23 & 4,9 & 1,6 \\
\hline Schizofreni & 30 & 3,5 & 1,6 & 32 & 3,5 & 1,6 \\
\hline Aids & 32 & 3,4 & 2,0 & 33 & 3,4 & 1,9 \\
\hline Psoriasis & 32 & 3,4 & 1,4 & 30 & 3,9 & 1,3 \\
\hline Anorexia nervosa & 34 & 3,3 & 1,4 & 33 & 3,4 & 1,5 \\
\hline Skrumplever & 34 & 3,3 & 1,8 & 35 & 3,2 & 1,6 \\
\hline Depressiv nevrose & 36 & 3,1 & 1,3 & 35 & 3,2 & 1,3 \\
\hline Angstnevrose & 37 & 2,8 & 1,3 & 37 & 2,9 & 1,4 \\
\hline Fibromyalgi & 38 & 2,6 & 1,4 & 38 & 2,4 & 1,3 \\
\hline Gjennomsnitt & & 5,0 & 1,5 & & 5,0 & 1,5 \\
\hline
\end{tabular}

\section{Hva er standardavvik?}

I tabell 1 vises standardavviket. Standardavvik forteller oss hva som ligger bak gjennomsnittsverdiene - gjennomsnittstallene kan skjule store variasjoner i dataene. I en 10-poengskala indikerer et standardavvik på rundt 1 eller mindre at det er stor enighet i svarene, det vil si lite avvik fra snittet. På den andre siden, et standardavvik på mer enn 2 forteller oss at det er stor spredning $i$ svardataene, det vil si mindre enighet i de avgitte svarene. 


\section{Rangering kan stride mot omsorgsverdier}

Likhetene i sykepleiernes og legenes vurderinger antyder at de rangerer sykdommer etter samme prinsipper.

Vi viste ovenfor at medisinsk kultur verdsetter sykdommer som blant annet er akutte, alvorlige, «objektive» og kurerbare. Felles for slike prestisjekriterier er at de reflekterer en «cure»- heller enn en «care»-tilnærming til helsearbeid (8).

Om det samme kan sies å gjelde for sykepleiernes rangeringer, vil dette stride med noen av profesjonens mest grunnleggende omsorgsverdier.

\section{Prestisjevurderinger kan få konsekvenser}

Selv om vi ikke direkte har undersøkt prestisjehierarkiets betydning for beslutningstaking, ser vi grunn til å tro at prestisjevurderinger kan ha betydning for hvordan sykepleiere møter pasienter.

Det kan blant annet tenkes at mange ansatte i helsevesenet, som andre steder, $\varnothing$ nsker å bli assosiert med prestisjefylte personer eller ting (12). Halvorsen, Førde og Nordtvedt har for eksempel vist at sykepleiere og leger på intensivavdelinger vier ekstra oppmerksomhet til «spennende» diagnoser (13).

\section{三 «Jo sjeldnere og mer dramatisk en sykdom var, dess større interesse og entusiasme ble den møtt med av både sykepleiere og leger.»}

Liknende funn er gjort på franske akuttmottak, der pasienter med «interessante» sykdommer ofte blir møtt med større entusiasme og får grundigere oppfølgning (14).

Jeg så også klare tendenser til dette i mitt eget feltarbeid på en norsk storbylegevakt: Der var det slik at jo sjeldnere og mer dramatisk en sykdom var, dess større interesse og entusiasme ble den møtt med av både sykepleiere og leger (15). 


\section{Delt kunnskap gir retning for handling}

Samtidig kan vi ikke ta for gitt at sykepleiernes vurderinger faktisk reflekterer sykepleiernes eget perspektiv. De er som nevnt blitt spurt om å vurdere sykdommene slik de tror «helsepersonell flest» ville gjort det. Hvorvidt, og i hvor stor grad, «helsepersonell flest» samsvarer med «sykepleiere flest», er et ubesvart spørsmål som fortjener videre forskning.

Det vi derimot vet, er at både leger og sykepleiere deler oppfatninger om hvordan helsepersonell flest ville rangert sykdommer. Denne delte kunnskapen kan antyde en utbredt enighet om hva slags sykdommer som verdsettes høyt og lavt i helsevesenet.

Et gjennomgående funn i sosiologisk og sosialpsykologisk forskning, er at slike delte verdsettingsordener kan ha stor betydning for folks beslutningstaking - uavhengig av om de selv slutter seg til denne måten å vurdere noe på $(16,17)$.

Hvis en sykepleier antar at «helsepersonell flest» holder noe for å være prestisjefylt, vil sykepleieren kunne legge disse oppfatningene til grunn for sine handlinger, uavhengig av om han eller hun personlig slutter seg til denne oppfatningen.

Mange forskere kan kjenne seg igjen i dette: De syns kanskje poengsystemet for publisering er noe tull, men de streber likevel etter å publisere i de mest prestisjefylte tidsskriftene fordi dette gir belønninger og ære fra andre.

\section{Sykepleiere må reflektere over egen praksis}

Prestisje er et fenomen som kan påvirke oss uten at vi merker det selv. Noe virker simpelthen riktigere, viktigere eller mer interessant enn noe annet, uten at vi helt kan sette fingeren på hvorfor (12).

\section{三 «Prestisje er et fenomen som kan påvirke oss uten at vi merker det selv.»}

Det er noe av grunnen til at det er så viktig å skape bevissthet rundt disse prestisjerangeringene - så sykepleiere og andre skal kunne bli oppmerksomme på dem, og tenke på hvordan de selv møter pasienter med ulike sykdommer. 
Vi oppfordrer derfor sykepleiere - individuelt og kollektivt til å reflektere over hvorvidt og hvordan sykdommers prestisje kan prege deres beslutningstaking. Tenk tilbake på den siste tidens pasienter: Har noen hatt mer eller mindre «spennende» eller «interessante» sykdommer enn andre, og kan det tenkes at det hadde betydning for hvordan du behandlet dem?

\section{Referanser}

1. Album D. Sykdommers og medisinske spesialiteters prestisje. Nordisk Medisin. 1991;106(8-9):232-6.

2. Album D, Westin S. Do diseases have a prestige hierarchy? A survey among physicians and medical students. Soc Sci Med. 2008;66(1):182-8. DOI:

10.1016/j.socscimed.2007.07.003

3. Album D, Johannessen LEF, Rasmussen EB. Stability and change in disease prestige: A comparative analysis of three surveys spanning a quarter of a century. Soc Sci Med. 2017;180:45-51. DOI: 10.1016/j.socscimed.2017.03.020

4. Haldar M, Engebretsen E, Album D. Legitimating the illegitimate: How doctors manage their knowledge of the prestige of diseases. Health (London). 2016;20(6):559-77. DOI: $\underline{10.1177 / 1363459315596798}$

5. Johannessen LEF. The narrative (re) production of prestige: How neurosurgeons teach medical students to valorise diseases. Soc Sci Med. 2014 november;120:85-91. DOI: $\underline{10.1016 / \mathrm{j} . \text { socscimed.2014.09.013 }}$

6. Johannessen LEF, Album D. Utenfor kroppen: kulturanalytiske studier av sykdom. I: Larsen H, red. Kultursosiologisk forskning. Oslo: Universitetsforlaget; 2015. s. $143-56$.

7. Johannessen LEF, Album D, Rasmussen EB. Do nurses rate diseases according to prestige? A survey study. J Adv Nurs. 2020;76(7)1691-7. DOI: 10.1111/jan.14394

8. Baumann AO, Deber RB, Silverman BE, Mallette CM. Who cares? Who cures? The ongoing debate in the provision of health care. J Adv Nurs. 1998;28:1040-5. https://doi.org/10.1046/j.1365-2648.1998.00809.x

9. Weber M. Makt og byråkrati: essays om politikk og klasse, samfunnsforskning og verdier. Oslo: Gyldendal; 2000. 
10. Album D. Den ene unders $\varnothing$ kelsen etter den andre. I: Album D, Hansen MN, Widerberg K, red. Metodene våre: eksempler fra samfunnsvitenskapelig forskning. Oslo: Universitetsforlaget; 2010. s. 253-69.

11. Treiman DJ. Occupational prestige in comparative perspective. New York: Academic Press; 1977.

12. Bourdieu P, Wacquant LJD. Refleksiv sociologi: mål og midler. København: Hans Reitzels Forlag; 1996.

13. Halvorsen K, Førde R, Nortvedt P. The principle of justice in patient priorities in the intensive care unit: The role of significant others. J Med Ethic. 2009;35(8):483-7. DOI: $\underline{10.1136 / \mathrm{jme} .2008 .028183}$

14. Dodier N, Camus A. Openness and specialisation: Dealing with patients in a hospital emergency service. Sociology of Health \& Illness. 1998;20(4):413-44. DOI: $\underline{10.1111 / 1467-9566.00109}$

15. Johannessen LEF. Narratives and gatekeeping: Making sense of triage nurses' practice. Sociology of Health \& Illness. 2018;40(5):892-906. DOI: 10.1111/1467-9566.12732

16. Mark NP, Smith-Lovin L, Ridgeway CL. Why do nominal characteristics acquire status value? A Minimal explanation for status construction. American Journal of Sociology. 2009;115(3):832-62. DOI: $10.1086 / 606142$

17. Willer R, Kuwabara K, Macy MW. The false enforcement of unpopular norms. American Journal of Sociology. 2009;115(2):451-90. DOI: 10.1086/599250 